\title{
THE PERCEIVED CHARACTERISTICS AND ADVANTAGES OF INFORMATION GAP ACTIVITIES IN LEARNING SPEAKING AT ENGLISHOPEDIA
}

\author{
Ana Resti Amalia \\ Islamic University of Indonesia \\ anarestilia@gmail.com
}

\begin{abstract}
In EFL context the necessity of English, chiefly speaking skill is demanded when it comes as requirement for continuing higher education and facing cross-cultural communication. Information gap activity is considered to imply for developing students' intelligence and ability to communicate and interact in real-situation. This research aims at explaining the implementation of information gap activities at Englishopedia and how students perceive the activities. The researcher used qualitative observational study, which the data were collected from observations, interview and documents. This research conducted in Englishopedia with 33 students during observation and 3 participants during interview were involved in this research. The research findings revealed that information gap activities facilitating the students in practicing speaking. The most prominent information gap activities were conversation through pair-work. Furthermore, the students were enthusiast in terms of pair-work activities, because it gave them new ideas, triggered to speak to other participants and enrollment of native speaker, thus establish students' motivation to learn and using English.
\end{abstract}

Keywords: Speaking skill; information gap activities; vocabulary learning

\section{BACKGROUND}

Ministerial Regulation in 2013 number 70 mentions about External Challenges that faces Indonesian students; globalization, limitless information and technology, creative industry development and international trade. These issues imply that Indonesian students in recent days need to be able to improve their speaking skill to use English for communication. Furthermore, refers to Indonesian National Qualification (KKNI), conceptually there are five points of the learning achievement; science, knowledge, skills, affection, competency, and practical knowledge. In terms of skills, speaking skill is required for learning achievement.

Speaking skill is divided into micro-skills and macro-skills. According to Brown (2001), micro-skills involve grammar, intonations, accuracy and fluency. Fluency is described as level of proficiency in communication. According to Abbaspour (2016) accuracy is the basis of fluency, while fluency is a further improvement of a person's 
linguistics competence. That is why, Nunan (2003) cited in Defrioka (2016) suggest the EFL teacher to provide the student to practice accuracy and fluency. Both of them are closely related that they are inseparable as a consequence speaking must be perceived as difficult for some people, especially in EFL context because speaking skill requires to some extent, it is demanding both fluency and accuracy all in together. The theories perceived that speaking as difficult skill to be mastered by EFL student. It caused by many factors, students feel hesitant to speaking in front of other students and students still lack in vocabulary. Information gap activities occurred as solution for the issues. In contrast, it would be difficult to encourage students to speak actively.

The successful speaking activities according to Ur (1996), include some points; learners talk a lot, participation is even, motivation is high, and language is acceptable level. Unfortunately, the reality showed that many college students in Indonesia still lack in speaking English. Some of them are aware of the importance if speaking English for communication. Manurung (2014) proved by his own research in Tadulako Univeristy, that speaking skill of college students are not satisfying and need to be improved. Ur (1996) stated some problems in speaking class. There are four problems; (1) Inhibition, students are avoiding to be the center of interest, because the fear of failure. (2) Nothing to say. Related to the point number one, fear of failure yields the students to think longer but at final they keep quiet and say nothing. (3) Low or uneven participation. The advanced student tends to be superior in the class by speaking actively. Meanwhile this affected other students which are not at the same level to feel hesitant and intimidated them. (4) Mother tongue uses. When students find it hard to speak in the target language, they preferred to use their first language as communication.

This is relevant with the condition at Englishopedia. Based on the first observation at Englishopedia, some of the students are undergraduate students and some of them are graduated students. Some the students worried, hesitant and anxious if they have to speak English to communicate with other people in real context or even to speak in speaking for any purpose. In the contrary, some of the students are capable to speak English. It has proven from the way they are talking, how they pronounce the words and through conversation. . However the aim of English teacher is to enable their students to speak English, therefore, the less-active students in speaking will be encouraged for practice their speaking.

In order to achieve the goal, the teacher should provide their students with maximum opportunity during the class. By giving more practice, contains collaborative or pair work, authentic material and task, and shared knowledge. By giving students opportunity to interact each other, it would help the student improve by communicating in real situation and focus on language content than language form. Englishopedia offers the new way in learning speaking. The tutor aware that speaking English played an important role recently thus, students need more practice speaking to reduce their hesitant, anxiety and enhance their confident while speaking English. Beside, Englishopedia provide the students to interact with native speaker and also with foreign speaker from other countries. It is important for knowing another culture as the preparation for the students face the new country in the future. They will know how to speak with the people from other country and learning another culture. It can be new atmosphere for the students to get experience to have a conversation with native 
speaker, get a reason to speak more and being their motivation to learn English. Sometimes students speak more willingly when they have a reason for communicating (Ismaili \& Bajrami, 2016).

Related to the speaking activities that implied at Englishopedia, collaborative or pair work and speaking in real context is very dominant. It is suitable with the characteristics of information gap activities, which requires students to use language in order to exchange information and get meaning across (Ismaili \& Bajrami, 2016). The table below presented the characteristics of information gap activities

Table 1 The characteristics of information gap activities

\begin{tabular}{lll}
\hline Kiato \& Kitao (1996) & Prabhu (1987) & Hasibuan (2012) \\
\hline Pair work & Transfer information & Expressing opinion \\
\hline Sharing information & Pair work & Obtaining information \\
\hline & Information selection & \\
\hline
\end{tabular}

Those researchers agree that information gap activities are designed for collaborative work. Kiato \& Kitao (1996) stated that information gap activity is used as communicative task to facilitate the students to work together. The task required students to ask and give more information they do not possess related to the context and then the knowledge will be equaled. They give an illustration about the information gap implementation. The activity involves more than one student to exchange the information by using simple context. For instance, the context is about buying a tape recorder, then they exchange the information based on the context of buying tape recorder.

Prabhu (1987) stated that information gap is one of three meaning-focused activities, and this activity involves asking and giving information. Information gap activity is the gap that has to be bridged by sharing in any constraint between students. Information gap activities involve sharing information from one person to another. $\mathrm{He}$ gives an example to do information gap in pair work when both students exchange the information. One student seems to be a resourceful person and another student is a clueless person. They have unequaled knowledge about the tape recorder, furthermore one student ask another student in order to obtain information about that.

These activities are integrated with speaking to emphasize the students to be active speaker. The activity stimulate the students in negotiating meaning, that is required the students to comprehend the context and speaking comprehensively. They stated that information gap can be used as a technique to encourage students in negotiating meaning. Through negotiation of meaning, the students would be interacted during the learning process by using the target language. In short, information gap activity involving students in starting meaning which is given to them from other students. By doing this activity, the students will get new insight from other students through interaction. Interaction helps in language development by facilitating students to talk to each other (Nation \& Newton, 2008). 
Concerning the issue above, students need a society that supports them to improve their speaking skill in real context. It means that they truly use English for communication and also use it in their environment. Englishopedia becomes a solution for them especially for college students in Yogyakarta to improve their speaking skill. At Englishopedia the students not only learn how to pronounce the words but they practice how to put the words for real situation. Students are communicating each other and close the gap between the, the result is students understand the material easily and being active to speak English.

\section{METHOD}

This research conducted by using observational study that is qualitative study. This research embedded observational study because it enables the researcher to investigate how information gap activity is perceived by students in learning speaking. It enables the researcher to do deep observation by doing observation in 3 different classes and recorded the whole class activity.

\section{Participants / Subject / Population and Sample}

This research involved college students from several universities in Yogyakarta as this research participants. This research depended on 33 students for observations, while 2 students and 1 tutor selected as respondents for interview. The respondents selected by attending the course more than a month and based on two categories; active student and passive student. The tutor selected as a respondent for interview, to give a brief statement and opinion about the learning process affected the students' improvement in speaking and considered that tutor played an important role as a facilitator in learning process.

\section{Instruments}

\section{Observation Tool}

This research attempts to answer these questions:

a. To what extent information gap activity is implemented at Englishopedia

b. How is the students' perception on the implementation of Information Gap Activities

The research data collected through observation and interview. By doing the observation, it gives rich data related how information gap activity is implemented in learning speaking. In conducting the observation, the researcher used 3 kinds of observation tools. The researcher used observation tool that adapted from Brown (2004) about 5 types of speaking, while in this research only used 3 types of speaking; responsive, intensive and interactive. Another observation tool adapted from Hasibuan (2012) and Prabhu (1987) theories related to the characteristics of information gap activities. The researcher took 5 points of the 7 total characters of information gap activities, based on some considerations from the class conditions and also the students'. The third observation tool used to know how information gap activity perceived by the students and how it affected students in learning speaking by adapted from Son (2009) as cited in Saputri (2010) about the advantages of information gap activity. 
Those observation tools used as main instruments in this research. As a result, some points were identified and investigated. Finally, the data that collected through observation were employed as main data in this research.

\section{Interview Questions}

The interview questions that implied in this research aims to give a data based on the individual perspective. The researcher measured several points by doing interview with 3 selected respondents. The respondents divided into 2; students and tutor as considered for enabling the researcher to elaborate the collected data from observation and to assess the students' perception before and after learning speaking at Englishopedia.

\section{Data Analysis}

Based on the data display, the researcher is presented the gathered data from observation and interview. There are 3 steps in doing data analysis. The first step is data reduction to reduce the data that is not relevant and could not be used for being evidence. The second step is data display, it is important how the researcher present the understandable data. The researcher is presented the data by showing the chart and interview result as supported data for the main data. Drawing conclusion is done after the researcher elaborated the collected data from observation and interview, is the data supported each other or not. While doing data analysis, the researcher distinguished the data based on types; observation and interview. The researcher used thematic analysis for analyzing the data as considered it simplifies to organize the data and analyze it in qualitative study.

\section{FINDINGS AND DISCUSSION}

a. Speaking Types

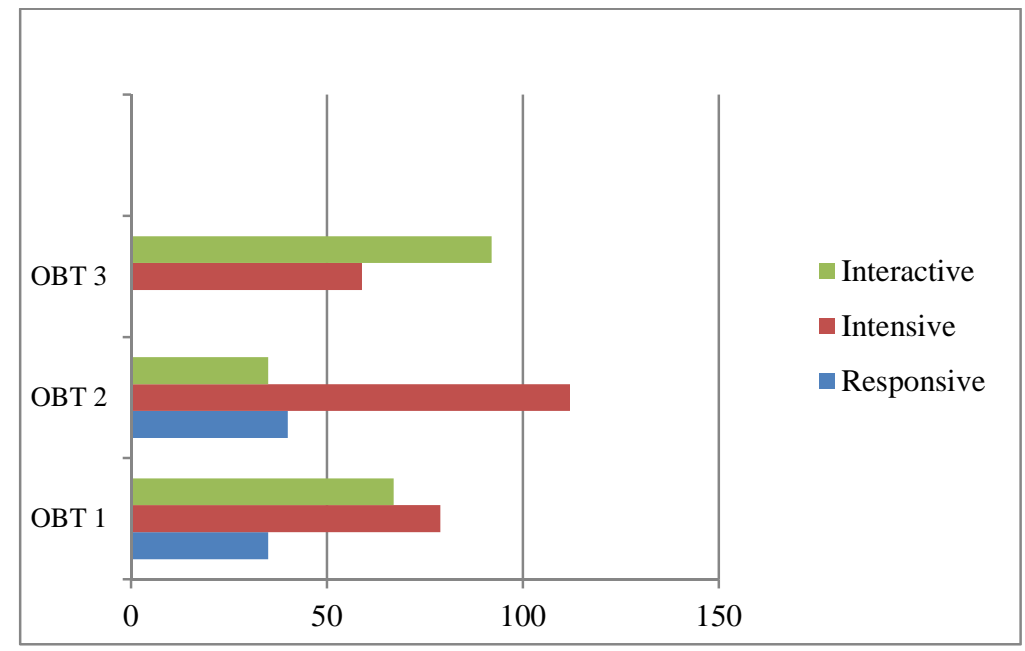

Figure 1. Observation analysis of speaking types

As shown in the figure 1, the collected data from observations revealed that 3 types of speaking only occurred in the observation 1 and 2, while in the observation 3 only 2 speaking types occurred. From all of the observation, responsive speaking was 
being the highest that occurred during observation. Intensive speaking was mostly occurred during vocabulary learning. According to Brown (2004), intensive speaking tends how students produce word, such as giving stress and intonation. Because of the criteria of this types, intensive speaking mostly occurred during vocabulary learning; pronunciation and talking-fast. During vocabulary learning, the students is trained how too day a word correctly. The figure 1, data revealed that intensive speaking increased from the first observation to the second observation, meanwhile in the third observation decreased because in the third observation the teacher focused on the interactive speaking. The researcher presented another data gathered from interview below.

"The objective of this class besides for the knowledge, I'd like to give more practice.My students have to practice because they can feel the improvement..." $(\mathrm{I} / 3 / \mathrm{ST} / 7)$

\section{"...we sharing opinion and also material too. It's fun to know what other people mind. And we were sharing ideas too." (I/2/ST/16)}

The data $(I / 3 / S T / 7)$ stated by the tutor of Englishopedia, that students' speaking improvement being the priority of this course. Because of that, the tutor played an important role as facilitator during the class and focuses on the practice that explaining material. Meanwhile, the statement $(I / 2 / S T / 16)$ stated by the students that supported the previous data that they were practicing by sharing opinion and ideas. It can be concluded that Englishopedia implied information gap activities by closing the students' gap in sharing their perspective about something they did not know before. It proved that the students speak "naturally" during learning process at Englishopedia.

"The first is grammar, second pronunciation and then speaking. Why I put the grammar first? Because I want to set the students' thoughts, so they can make a sentence in the correct order not only speak by ignoring grammar." $(\mathrm{I} / 3 / \mathrm{ST} / 5)$

The statement above, revealed that Englishopedia aware that grammar is important too for the students. Without grammar, the students will speak randomly. It is supported by Levelt as cited in Abbaspour (2016) there 3 points in learning speaking; conceptualization, formulation, and articulation. However this class focuses on speaking skill, the tutor aware that grammar lesson is important too, thus the teacher started the class by delivering grammar lesson first and will continue with pronunciation and speaking session. Speaking caused the students ignore the English structure as stated by Ismaili \& Bajrami (2016) "it (speaking) takes students' attention away from English structure".

Beside the grammar lesson, pronunciation played an important role in improving students' speaking skill. During pronunciation, the tutor guided the students' articulation and showed them how to spell the words correctly. Pronunciation and vocabulary are important factors to be emphasized in building students' fluency for EFL learners (Boonkit, 2010). Supported by Kayi (2007) in Defrioka (2016), before entering speaking session, it would be better for the teacher to diagnose the students' obstacle in 
speaking. The data revealed based on the observation that students quiet hard to speak English due to lack in vocabulary and pronunciation, thus Englishopedia provide the students with grammar lesson, vocabulary and pronunciation session to help students acquired the language first. After that, teacher as facilitator and guide the students during speaking session.

\section{"...we sharing opinion and also material too. It's fun to know what other people mind. And we were sharing ideas too." (I/2/ST/16)}

Move to speaking session, the tutor designed the class into pair and then the students will speak each other for speaking practice. In this session, interactive speaking most occurred during the class. Because the students will share their perspective and ideas, it aims to communicate in English as a part in maintaining social interaction. Understanding the context, speaking accurately and sharing opinion or thoughts are required (Brown, 2004).

\section{b. Characteristics of Information Gap Activities}

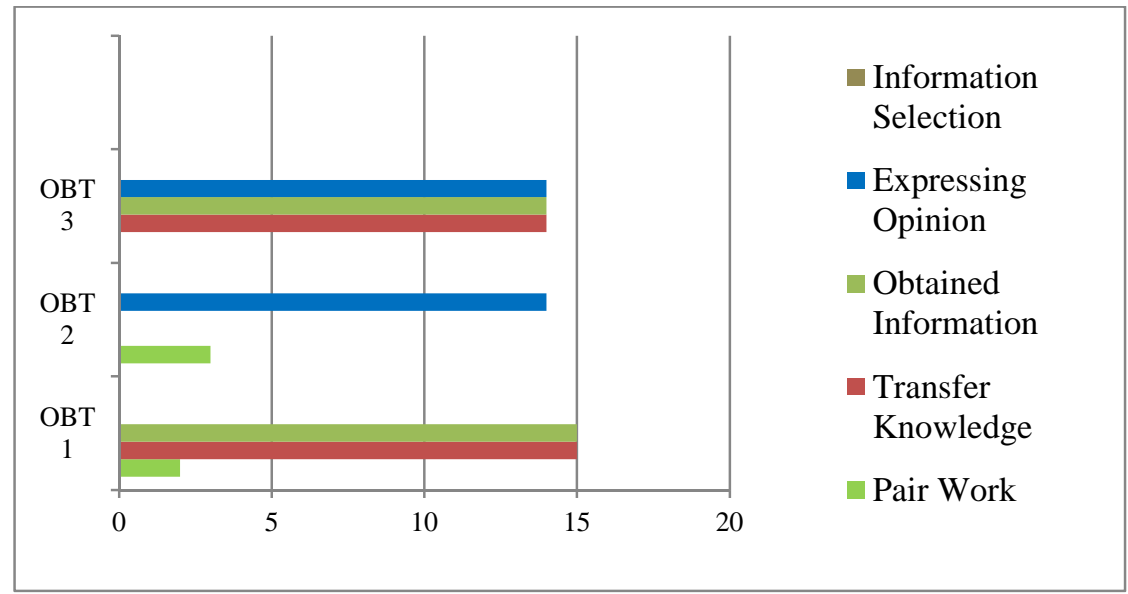

Figure 2. Observation analysis of information gap characteristics

The data result of observation has displayed in figure 2. The figure 2 revealed that not all points occurred during observation as affected by some conditions in the class. In the observation 1 there were 3 points occurred, included pair-work, transferknowledge and obtained-information.in the observation 2, there were 2 points occurred; expressing-opinion and pair-work. Meanwhile in observation 3 the occurred points were expressing-opinion, transfer-knowledge and obtained-information. The characteristics of information gap activity mostly appeared during speaking session. During the speaking session, the teacher announced that each 10 minutes the partner would be changed and they would begin to discuss new topic. In this meeting, the teacher have chosen three topics; what will you in Saturday and Sunday, what will you do if you are the most beautiful/handsome, and the last what will you do if you are rich people. The students practiced their speaking ability with their friends or while they had a discussion with the foreign speaker from other countries. 


\section{"Yes, because pair-work is really help me to improve my speaking skill..." (I/1/CIGA/26)}

"Hmmm, no. actually I joined Englishopedia only by myself. So I didn't know the other students at the first time. So ya I was trying to have a discussion with many students too. I try to be welcomed to another student, have conversation even I don't interested with some topics but ya it's fun." (I/2/CIGA/13)

Based on the result above, it proved that the characteristics of information gap activities appeared during learning speaking at Englishopedia. It can be concluded that the tutor implied discussion and pair-work to encourage students in speaking English and it influenced the students better in encouraging the students to speak more in the class.

\section{c. Advantages of Information Gap Activity}

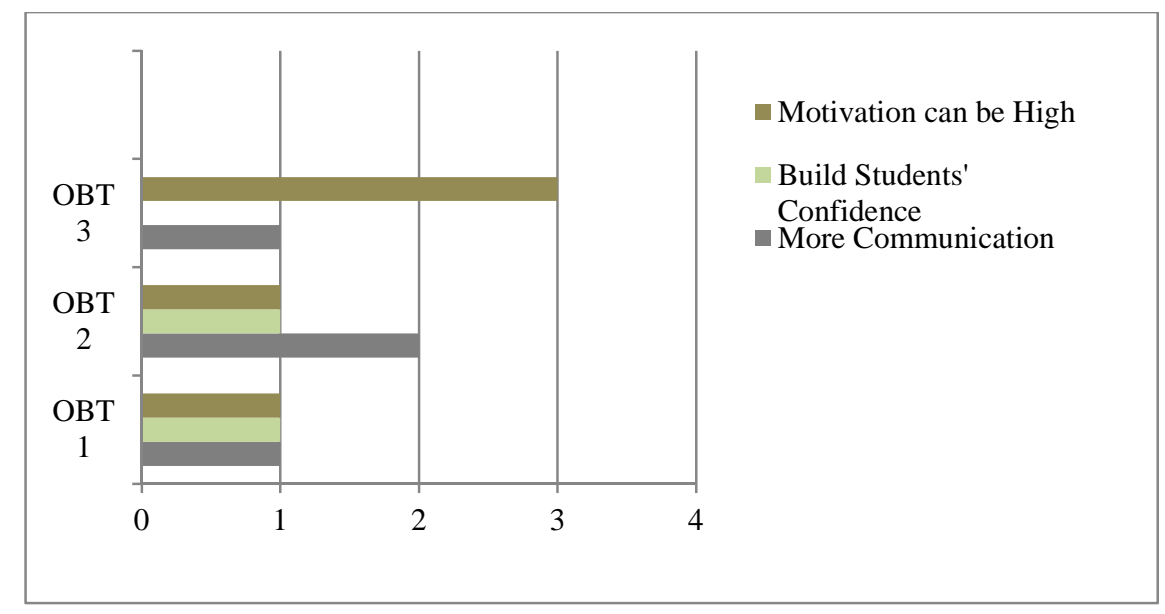

Figure 3. Observation analysis of information gap advantages.

According to the table above presented the advantages of information gap activity at Engslishopedia. The data showed all three points that included occurred in this observation. Those points are more communication, build students' confidence, and motivation can be high.

"Yes, because pair work is really help me to improve my speaking skill. It builds my confidence and the teacher encourages us to speak confidently." (I/1/AIGA/26)

\section{"Because, when I speak to another people I feel like brain freeze 'what I suppose to talk about?' but in here I have learned how to speak to another people, so it's better." (I/2/AIGA/9)}

Son (2009) as cited in Saputri (2010) mentioned the advantages of information gap activity included motivation be high, build students' confidence and build more 
communication. The figure 3 showed how information gap activities bring advantages for the students in learning. In the observation 1 all points occurred equally. In observation 2 communications occurred as the highest point meanwhile in observation 2 only 2 points occurred; motivation is high and more communication.

From this, it can be seen that information gap activities have considerable influence in students' speaking improvement. By doing practice speaking, it considered as effective way to eliminate fear of making errors and build up students' confidence (Boonkit, 2010). Despite information gap activity could not enhanced students' speaking skill significantly, by implementing information gap activities students had more opportunities to speak more in practice speaking and it proved by the students' statement in (I/1/AIGA/9) and (I/2/AIGA/9). It proved that the students were more active during the class.

\section{CONCLUSION}

From the result in data findings and discussion, it can be conclude that the extent of using information gap activity at Englishopedia to help students in learning interactive speaking. Learning speaking at Englishopedia conducted in pair-work and discussion which gave students to speak more actively by asking another students' perception and ideas about something. The activities required the students speak actively by using target language which trained their speaking ability, pronunciation and reduced their anxiety in speaking English. The technique used in learning speaking has an important role because it has to facilitate students to practice speaking. By using communicative task, the students not only gained the language structure but acquire language usage in real context. Kitao \& Kitao (1996) stated that communicative language tested have to measure how the students are able to use language in a real situation. Involving the students in many activities and engaged them to interact with other students will help them in order to enhance their speaking skill. In short, while students speaking English continuously it is effective to encourage students in speaking English and confidently. It gives students opportunity to speak and interact with native speaker, and then it gives more benefits for students in learning other cultures and earns new insights in terms of preparation in facing cross-cultural communication.

It can be stated that the activities at Englishopedia indicated as the characteristics of information gap activities and designed for students to speak more willingly and actively. It is much more efficient for student in practice speaking and able to learn new culture from another country. Students proved more engaged and often excited while students working together and help each other. 


\section{REFERENCES}

Abbaspour, F. (2016). Speaking competence and its components: A literature review. International Journal of Research in Linguistics, Language Teaching and Testing, $1(4), 144-152$.

Boonkit, Kamonpan. (2010). Enhancing the development of speaking skills for nonnative speakers of English. Procedia Social and Behavioral Sciences 2 (2010). 1305-1309. doi: 10.1016/j.sbspro.2010.03191

Brown, H. (2001). Teaching by principles: An interactive approach to language pedagogy. NY: Addison-Wesley: White Plains

Brown, H. (2004). Language assessment: Principles and classroom practices. New York: Longman

Defrioka, A. (2016). The use information gap activities in teaching speaking (classroom action research in SMK). Jurnal Pembelajaran dan Bahasa (Lingua Didaktika), . 10(2). 116-126. doi: http://ejournal.unp.ac.id/index.php/lingudidaktika/

Hasibuan, K. (2012). Teaching speaking as a productive skill. Journal of English and Arabic Language Teaching (JEALT), 3(1). http://ejournal.uinsuska.ac.id/index.php/jealt/article/view/139

Ismaili, M., \& Bajrami, L. (2016) Information gap activities to enhance speaking skills of elementary level students. International Conference on Teaching and Learning English as an Additional Language, GlobELT, 232, 612-616. doi: https://doi.org/10.1016/j.sbspro.2016.10.084

Kitao, K. S., \& Kitao, K. (1996). Testing communicative competence. The Internet TESL Journal, 11(5), Retrieved from https://eric.ed.gov/?id=ED398260

Manurung, K. (2014). Improving the speaking skill using reading contextual internetbased instructional materials in an EFL class in Indonesia. International Educational Technology Conference, IETC, 176, 44-51. doi: https://doi.org/10.1016/j.sbspro.2015.01.442

Prabhu, N. (1987). Second language pedagogy. Oxford: Oxford University Press

Saputri, H. (2010). The effect of using information gap activities towards motivation in speaking English among year student at MAN 2 Model Pekanbaru. A Thesis for Bachelor Degree at State University Riau

Ur, Penny. (1996). A Course in Language Teaching Practice and Theory. Cambridge Teacher Training and Development.

Utomo, W., \& Margana. (2016). Improving students' speaking skill through information gap activities in XI MIA 3 of SMA Muhammadiyah 2 Yogyakarta in academic year of 2015/2016. English Language Teaching Journal, 5(7). Retrieved from http://journal.student.uny.ac.id/ojs/index.php/elt/article/view/4847/0 